\title{
Penyuluhan Budidaya Padi Ladang Varietas Unggul Di Desa Efi-Efi Kecamatan Tobelo Selatan
}

\author{
Ariance Yeane Kastanja ${ }^{1}$, Zeth Patty ${ }^{2}$, Nonice Manikome ${ }^{3}$, Zakarias Dilago ${ }^{4}$ \\ ${ }^{1}$ Fakultas Sains dan Kesehatan, Universitas Hein Namotemo \\ Email: ariance1401@gmail.com \\ ${ }^{2}$ Fakultas Sains dan Kesehatan, Universitas Hein Namotemo. \\ Email: zethpatty4@gmail.com \\ ${ }^{3}$ Fakultas Sains dan Kesehatan, Universitas Hein Namotemo. \\ Email: nicemanikome@yahoo.co.id \\ ${ }^{4}$ Program Studi Budidaya Hutan, Politeknik Perdamaian Halmahera, \\ Email: zakariasdilago@gmail.com
}

\begin{abstract}
This community service activity is carried out in the Efi-Efi Village, South Tobelo District, with the aim of providing skills and knowledge to farmers both about the use of high yielding variety of upland rice seeds and good upland rice cultivation techniques. The method used in this service is counseling about the cultivation of upland rice, the provision of high yielding variety of upland rice seeds and agricultural equipment and the making of high yielding variety of upland rice demonstration plots. Participants in this activity are the farmer women's group Efi-Efi, amounting to 20 members, who have been planting varieties of local upland rice. The results of the evaluation of community service activities showed that the knowledge and skills of the groups of women farmers who cultivated field rice had increased, and farmers accepted the use of high yielding variety of upland rice seeds introduced to them. In addition, there has also been a change in understanding in terms of shifting cultivation as has been done so far.
\end{abstract}

Keywords: Women Farmers, upland rice, high yielding variety, Efi-Efi Village.

\begin{abstract}
Abstrak
Kegiatan pengabdian masyarakat ini dilakukan di Desa Efi-Efi Kecamatan Tobelo Selatan, dengan tujuan untuk memberi keterampilan maupun pengetahuan bagi petani baik tentang penggunaan benih padi ladang varietas unggul maupun teknik budidaya padi ladang yang baik. Metode yang digunakan dalam kegiatan pengabdian ini adalah penyuluhan tentang budidaya padi ladang, pemberian bantuan benih padi ladang varietas unggul dan peralatan pertanian serta pembuatan demplot padi ladang varietas unggul. Peserta kegiatan ini adalah kelompok perempuan tani Desa Efi-Efi yang berjumlah 20 orang anggota, yang selama ini menanam padi ladang varietas local. Hasil evaluasi kegiatan pengabdian menunjukkan bahwa telah meningkatnya pengetahuan dan ketrampilan kelompok perempuan tani yang membudidayakan padi ladang, serta petani menerima penggunaan benih padi ladang varietas unggul yang diperkenalkan bagi mereka. Selain itu juga terjadi perubahan pemahaman dalam hal ladang berpindah seperti yang dilakukan selama ini
\end{abstract}

Kata Kunci: Perempuan Tani, Padi Ladang, Varietas Unggul, Desa Efi-Efi.

\section{PENDAHULUAN}

Penduduk di Kabupaten

Halmahera Utara sebagian besar

berprofesi sebagai petani terutama petani kelapa. Hal ini didukung oleh ketersediaan lahan yang sangat luas, yakni lahan pertanian seluas 130.035 ha, sisanya seluas 103.247 ha 
tercatat sebagai lahan yang belum diolah. Selain tanaman kelapa sebagai tanaman utama, para petani juga mengusahakan berbagai jenis tanaman pertanian lainnya, baik tanaman perkebunan maupun tanaman pangan.

Salah satu tanaman pangan yang juga diusahakan turun temurun adalah padi ladang, yang biasanya ditanam oleh perempuan tani. Padi ladang dikenal oleh masyarakat Halmahera Utara dengan sebutan "Padi Beras Baru", yang diusahakan untuk mendukung ketersediaan pangan rumah tangganya. Tanaman padi ladang di Halmahera Utara memiliki luas lahan 5.900 ha, dengan luas panen 2.806 ha dan produksi sebesar 6.314 ton (BPS Kab. Halmahera Utara, 2020).

Pengusahaan padi ladang masih dilakukan secara tradisional dengan sistem berpindah-pindah tempat, dimana pembukaan hutan dilakukan dengan cara menebang dan membakar. Pemanfaatan lahan seperti ini meningkatkan potensi penggundulan hutan dan berakibat pada rusaknya hutan bahkan dapat mengakibatkan rusaknya ekosistem hutan. Hal ini sejalan dengan pendapat (Sulistinah, 2014), bahwa dampak fisik dan lingkungan dari ladang berpindah mengakibatkan penurunan kesuburan tanah hingga terjadinya kekeringan pada musim kemaruau serta banjir pada musim hujan.

Selain itu pemanfaatan areal kosong diantara tanaman kelapa belum dimanfaatkan secara optimal. Umumnya sebagian petani mengisinya dengan berbagai jenis tanaman perkebunan seperti pala, kakao sebagai tanaman sela, tetapi sebagian petani yang lain membiarkan lahannya tertutupi gulma bahkan tidak termanfaatkan.

Desa Efi-Efi terletak pada wilayah Kecamatan Tobelo Selatan. Tanaman yang banyak dikembangkan di lokasi ini adalah tanaman perkebunan, tanaman hortikultura, maupun tanaman pangan seperti padi. Luas panen padi ladang di Kecamatan Tobelo Selatan ini adalah 179 Ha (BPS Kab. Halmahera Utara, 2019). Jumlah kepala keluarga di Desa Efi-Efi adalah 363 KK, dengan jumlah penduduk sebanyak 1.229 orang, jumlah laki-laki sebanyak 612 orang dan perempuan sebanyak 617 orang (Kour, Akerina, \& Dilago, 2020).

Desa ini dipilih sebagai tempat pelaksanaan kegiatan karena potensi lahan yang dimiliki serta banyaknya kelompok petani perempuan yang melakukan budidaya padi ladang varietas lokal dengan potensi produksi yang rendah. Benih padi ladang yang dijadikan bahan tanam 
kebanyakan merupakan benih yang berasal dari hasil panen sebelumnya (Kastanja, 2011).

Saat ini petani di Desa Efi-Efi masih menggunakan benih lokal yang potensi produksinya rendah serta teknik budidaya tanpa menggunakan pupuk. Hal ini karena petani kesulitan mendapatkan benih yang bermutu serta ketidaktahuan dalam penggunaan pupuk baik organik maupun anorganik. Penggunaan lahan yang berpindah-pindah tempat menjadi alasan bagi petani untuk mendapatkan lahan yang subur.

Tujuan kegiatan pengabdian untuk memberi informasi maupun pengetahuan bagi petani baik tentang penggunaan benih padi ladang varietas unggul serta teknik budidaya padi ladang yang baik.

\section{METODE PELAKSANAAN}

Kegiatan ini dilaksanakan di Desa Efi-Efi Kecamatan Tobelo Selatan, selama 4 bulan. Metode yang digunakan dalam kegiatan pengabdian ini adalah penyuluhan tentang budidaya padi ladang, pemberian bantuan benih padi varietas unggul dan peralatan pertanian serta pembuatan demplot padi ladang Varietas Situ Bagendit.

Penyuluhan merupakan upaya-upaya yang dilakukan untuk mendorong terjadinya perubahan perilaku pada individu, kelompok, komunitas, ataupun masyarakat agar mereka tahu, mau, dan mampu menyelesaikan permasalahan yang dihadapi (Amanah, 2007), sedangkan pelatihan adalah upaya yang dilakukan untuk meningkatkan kemampuan dan ketrampilan kerja (Nababan, Tawas, \& Uhing, 2016). Peningkatan pengetahuan, keterampilan, perubahan sikap serta hal-hal yang dapat menjadi perbaikan bagi peningkatan kinerja dan produktivitas dalam memberdayakan petani dapat dilakukan melaui pelatihanpelatihan (Putri \& Amanah, 2016)

Jenis padi ladang yang diperkenalkan adalah padi ladang Varietas Situ Bangendit yang didatangkan dari Jawa untuk diintroduksi pada petani padi ladang lokal daerah ini.

\section{HASIL DAN PEMBAHASAN}

\subsection{Penyuluhan Budidaya Padi}

\section{Ladang}

Kegiatan Penyuluhan

budidaya padi ladang disampaikan kepada peserta untuk meningkatkan pemahaman dan pengetahuan mereka. Materi yang disampaikan mencakup pengetahuan tentang padi ladang varietas unggul, mencakup syarat tumbuh, pemilihan benih, pemupukan serta pemanenan tanaman padi ladang. 
Peserta dalam kegiatan penyuluhan adalah kelompok perempuan tani yang aktif melakukan budidaya padi ladang varietas lokal di Desa Efi-Efi, dengan umur bervariasi mulai dari 30 tahun hingga umur 60 tahun. Data tentang jumlah dan umur peserta ditampilkan pada tabel 1 .

Tabel 1. Peserta Kegiatan Penyuluhan berdasarkan Umur

\begin{tabular}{cc}
\hline $\begin{array}{c}\text { Umur } \\
\text { (Tahun) }\end{array}$ & Jumlah (Orang) \\
\hline $30-40$ & 4 \\
$41-50$ & 3 \\
$51-60$ & 13 \\
\hline
\end{tabular}

Sumber ; Data Primer

Dalam kegiatan penyuluhan dijelaskan antara lain tentang jenisjenis padi ladang dan syarat tumbuh dan teknik budidaya serta penjelasan tentang padi ladang Varietas Situ Bagendit. Padi ladang atau biasa dikenal dengan padi gogo merupakan padi yang ditanam pada lahan kering dan dilakukan secara berpindah-pindah tempat. Menurut Yuniarti,(2015), padi gogo merupakan jenis padi pada lahan kering yang sumber airnya berasal dari curah hujan.

Menurut (Sujitno, Fahmi, \& Teddy, 2011), jenis-jenis padi ladang varietas unggul antara lain adalah Situ Patenggang, Situ Bagendit, Limboto, Towuti dan Batu Tegi. Selanjutnya dikatakan bahwa hasil produksi keempat varietas padi gogo tersebut bervariasi. Lebih lanjut
(Suriansyah, Suarman, Bhermana, \& Anto, 2013), menyatakan benih, dalam hal ini varietas merupakan faktor penting dalam budidaya padi ladang.

Secara umum padi ladang dapat tumbuh dengan baik pada curah hujan 875 - $1000 \mathrm{~mm}$ per tahun dan suhu $24-26^{\circ} \mathrm{C}$, dengan jenis lahan bertopografi datar hingga bergelombang (Yuliyanto \& Sudibyakto, 2012). Berikut disajikan Gambar 1 tentang kegiatan penyuluhan budidaya padi ladang kepada kelompok perempuan tani di Desa Efi-Efi.

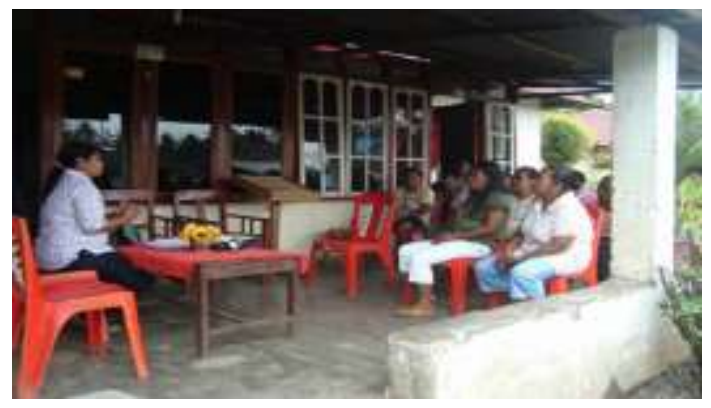

Gambar 1. Penyuluhan Tentang Budidaya Padi Ladang 
Secara umum penanaman padi dilakukan secara tugal dengan jumlah 5 benih per lubang dan jarak tanam $20 \times 30 \mathrm{~cm}$. Benih yang dipilih sebaiknya benih unggul yang menghasilkan produksi tinggi. Hal ini berbeda dengan kebiasaan petani lokal di Desa Efi-Efi. Hasil diskusi dengan petani saat penyuluhan menunjukkan bahwa petani teknik penanaman biasanya dilakukan dengan sistem tugal, dimana jumlah benih yang dimasukkan ke lubang tanam berkisar antara 5 - 10 benih, bahkan bisa lebih. Petani berpendapat dengan banyaknya jumlah benih per lubang tanam, maka peluang padi yang tumbuh menjadi lebih banyak sehingga hasilnya juga banyak. Saat penyuluhan tersebut barulah petani memperoleh pengetahuan tentang pembentukan anakan primer dan sekunder yang membentuk rumpun padi. Jika jumlah benih dalam lubang tanam banyak, maka akan terjadi persaingan untuk memperoleh ruang tumbuh, akibatnya pertumbuhan tunas primer dan sekunder tidak maksimal (Sutoro, Suhartini, Setyowati, \& Trijatmiko, 2016)

Sistem budidaya Padi ladang di Halmahera dilakukan dengan sistem berpindah tempat. Menurut informasi hal ini dilakukan oleh petani selain untuk mendapatkan sumber hara yang baik bagi tanaman, budidaya berpindah tempat ini dilakukan dengan tujuan membuka lahan yang baru untuk selanjutnya setelah panen padi ladang dilakukan dilanjutkan dengan penanaman tanaman perkebunan seperti kelapa dan pala.

Selain mendapatkan penjelasan tentang teknik budidaya padi ladang, petani juga mendapatkan penjelasan tentang dampak buruk perladangan berpindah. Hal ini karena Masyarakat Halmahera selama ini menerapkan sistem perladangan berpindah secara turun temurun, dengan menanam berbagai jenis tanaman pangan seperti padi, ubi-ubian dan kacang-kacangan. Hal yang sama juga dilakukan petani padi ladang yang masih melakukan kebiasaan perladangan berpindah saat membuka lahan untuk penanaman padi ladang varietas lokal.

Hal tentang dampak buruk ini sesuai dengan pendapat (Sulistinah, 2014), yang menjelaskan bahwa perladangan berpindah dapat memberikan dampak buruk terhadap kesuburan tanah, kerusakan lingkungan, banjir pada musim hujan dan kekeringan pada musim kemarau serta terjadinya perubahan iklim mikro dan gangguan habit pada areal tersebut.

Hasil evaluasi penyuluhan menunjukkan peserta dapat mengetahui cara budidaya padi 
ladang Situ Bagendit dengan baik.

pada tabel 2 di bawah ini. Hasil evaluasi ini ditampilkan

Tabel. 2. Hasil Evaluasi Teknik Budidaya Padi Ladang

\begin{tabular}{lcc}
\hline \multirow{2}{*}{ Indikator } & \multicolumn{2}{c}{ Evaluasi Teknik Budidaya Padi ladang } \\
\cline { 2 - 3 } & Sebelum penyuluhan & Sesudah penyuluhan \\
\hline Varietas & Lokal & Situ Bagendit \\
Jarak Tanam & Tidak teratur & $20 \times 30$ \\
Benih / lubang tanam & $5-10$ & 5 \\
Cara berkebun & Ladang berpindah & Lahan tetap \\
\hline
\end{tabular}

Sumber : hasil wawancara

\subsection{Penyerahan Benih dan \\ Peralatan Pertanian}

Untuk mendukung kegiatan penyuluhan dan pembuatan demplot, maka petani diberikan bantuan benih padi ladang unggul varietas Situ Bagendit dan peralatan. Jenis peralatan yang diserahkan ditampilkan pada tabel 3.

Tabel 3. Peralatan yang diserahkan

\begin{tabular}{lll}
\hline Uraian & Jumlah & Satuan \\
\hline Benih Padi & 50 & $\mathrm{Kg}$ \\
Parang & 10 & Unit \\
Pacul & 10 & Unit \\
Spayer & 2 & Unit \\
Hitter/ Gembor & 10 & Unit \\
Herbisida & 4 & Botol \\
Pisau & 10 & Unit \\
\hline
\end{tabular}

Berikut disajikan Gambar 2 tentang kegiatan penyerahan bantuan benih padi ladang varietas unggul dan peralatan kepada kelompok perempuan tani di Desa Efi-Efi.

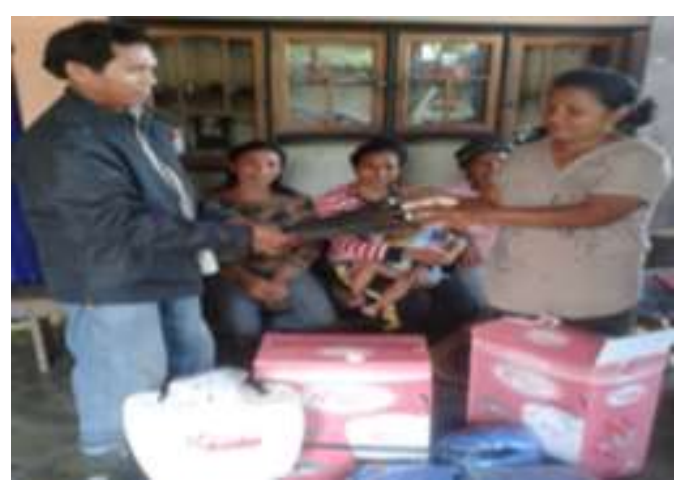

Gambar 2. Penyerahan Bantuan Benih dan Peralatan Pertanian

\subsection{Pembuatan Demplot}

Demplot atau Demontration Plot adalah suatu metode penyuluhan pertanian kepada, dengan cara membuat lahan percontohan, agar petani bisa melihat dan membuktikan terhadap objek yang didemontrasikan. Demplot bisa berupa inovasi teknologi budidaya, varietas unggul baru, pemupukan dan lain-lain, disesuaikan dengan kebutuhan petani (Gunungpati, 2018).

Pembuatan demplot bertujuan untuk memperkenalkan variaetas baru kepada petani serta membantu 
membimbing petani kearah usahatani yang lebih baik, serta mendorong tumbuhnya kepercayaan petani terhadap hal baru (Suriansyah et al., 2013)

Kegiatan pembuatan demplot kali ini dilaksanakan untuk memberikan contoh secara nyata tentang proses budidaya padi ladang varietas Situ bagendit kepada petani. Pembuatan demplot dilakukan oleh kelompok perempuan tani di Desa Efi-Efi dibantu oleh 5 orang mahasiswa, yang diawali dengan pembersihan lokasi yang akan ditanami seluas 0,25 ha pada lahan milik ketua kelompok.

Setelah pembersihan lahan, kemudian dibuat larikan menggunakan tali dan dilanjutkan dengan pembuatan lubang tanam dengan tugal, sekaligus benih padi dimasukan ke lubang tanam sebanyak 5 benih dan ditutup tanah kembali.

Pemupukan dilakukan 3 tahap, dimana pemupukan pertama dilakukan setelah tanaman padi berumur 10 hari. Pemupukan kedua dilakukan saat tanaman berumur 35 hari, dan pemupukan ketiga saat tanaman berumur 55 hari (Prasetyo, 2006). Pemupukan dilakukan dengan cara menempatkan pupuk dekat dengan lubang tanam dan kemudian ditutup dengan tanah.
Kegiatan penyiangan gulma dilakukan pada saat tanaman berumur 3 minggu. Pengendalian dilakukan dengan cara mencabut atau mencangkul gulma yang tumbuh disekitar tanaman padi. Sedangkan untuk pengendalian hama dan penyakit dilakukan jika tanaman terindikasi mengalami serangan.

Kegiatan panen dilakukan saat tanaman mencapai umur \pm 120 hari, dan menunjukkan tingkat kematangan butir padi. Tandatanda padi ladang telah mencapai waktu panen antara lain; seluruh bagian tanaman telah menguning, batang mengering, gabah telah mengeras (Prasetyo, 2006).

\section{PENUTUP}

Kegiatan pengabdian ini telah memberi pengetahuan dan keterampilan bagi kelompok perempuan tani yang membudidayakan padi ladang di Desa Efi-Efi, sekaligus telah

Memperkenalkan varietas padi ladang unggul pada masyarakat di desa tersebut serta mampu mendorong masyarakat untuk memperbaiki kebiasaan berladang secara berpindah.

\section{DAFTAR PUSTAKA}

Amanah, S. (2007). Makna Penyuluhan dan Transformasi Perilaku Manusia. Jurnal 
Penyuluhan, 3(1), 5. https://doi.org/10.25015/peny uluhan.v3i1.2152

BPS Kab. Halmahera Utara. (2019). Tobelo Selatan dalam Angka (No. 82050.1910). Tobelo.

BPS Kab. Halmahera Utara. (2020). Kabupaten Halmahera Utara Dalam Angka (No. 82050.2004). Tobelo. Retrieved from https:/ / halutkab.bps.go.id/pu blication.html

Gunungpati, B. (2018). Demplot Sayuran dan Toga Organik di BPP Gunungpati. Retrieved June 16, 2020, from https:/ / dispertan.semarangkot a.go.id/demplot-sayurangunungpati/

Kastanja, A. Y. (2011). Kajian Penerapan Teknik Budidaya Padi Gogo Varietas Lokal (Studi Kasus pada 4 kecamatan di Kabupaten Halmahera Utara). Jurnal Agroforestri, VI(2), 121-128.

Kour, F., Akerina, F. O., \& Dilago, Z. (2020). Analisis Sosial Ekonomi Masyarakat Nelayan di Desa Efi-Efi Kecamatan Tobelo Selatan Halmahera Utara ( Social Economy Analysis of Fishing Community in Efi-Efi Vilage ,. Agrikan: Jurnal Agribisnis Perikanan, 13(1), 3845.

https://doi.org/10.29239/j.agri kan.13.2.

Nababan, Y., Tawas, H., \& Uhing, J. (2016). Pengaruh Pendidikan
Dan Pelatihan Kerja Terhadap Kinerja Karyawan Pt.Pln (Persero) Area Manado. Jurnal Riset Ekonomi, Manajemen, Bisnis Dan Akuntansi, 4(3), 751-759.

Prasetyo. (2006). Bertanam Padi Gogo Tanpa Olah Tanah (edisi revi). Jakarta: Penebar Swadaya.

Putri, I. W., \& Amanah, S. (2016). Pengaruh Pelatihan Non Teknis terhadap Kinerja Penyuluh Pertanian BP4K di Kabupaten Bungo Provinsi Jambi, 12(1), 43-50.

Sujitno, E., Fahmi, T., \& Teddy, S. (2011). Kajian Adaptasi Beberapa Varietas Unggul Padi Gogo Pada Lahan Kering Dataran Rendah Di Kabupaten Garut. Jurnal Pengkajian Dan Pengembangan Teknologi Pertanian, 14(1), 62-69.

Sulistinah. (2014). Dampak Perladangan Berpindah Pada Ekosistem Dan Lingkungan Hutan. Jurnal Geografi, 12(2), 143-157.

Suriansyah, Suarman, Bhermana, A., \& Anto, A. (2013). Petunjuk Teknis Pengelolaan Tanaman Terpadu (PTT) Padi Gogo. Palangka Raya

Sutoro, N., Suhartini, T., Setyowati, M., \& Trijatmiko, K. R. (2016).

Keragaman Malai Anakan dan Hubungannya dengan Hasil Padi Sawah (Oryza sativa). Buletin Plasma Nutfah, 21(1), 9. https://doi.org/10.21082/blpn. v21n1.2015.p9-16 
Yuliyanto, \& Sudibyakto. (2012).

Kajian Dampak Variabilitas

Curah Hujan Terhadap

Produktivitas Padi Sawah

Tadah Hujan Di Kabupaten

Magelang. Jurnal Bumi

Indonesia, 1(1), 55. Retrieved

from

http://lib.geo.ugm.ac.id/ojs/in dex.php/jbi/article/view/37

Yuniarti, S. (2015). Respon pertumbuhan dan hasil varietas unggul baru (VUB) padi gogo di Kabupaten Pandeglang, Banten. In SEMNAS Biodiversity Indonesia (Vol. 1, pp. 848-851). https://doi.org/10.13057/psn $\mathrm{mbi} / \mathrm{m} 010432$ 